\title{
A saúde mental na percepção de estagiários: Uma revisão de literatura
}

\author{
Mental health by the perception of trainees: A literature review
}

Bruna Maria Coelho Freitas ${ }^{[a]}$, Leonardo Martins Kebbe $e^{[b]}$

\footnotetext{
[a] Graduada em Terapia Ocupacional pela Universidade de São Paulo (USP), câmpus Ribeirão Preto, terapeuta ocupacional no Ambulatório de Saúde Mental da Prefeitura Municipal de Sorocaba, Sorocaba, SP - Brasil, e-mail: bmcfreitas@yahoo.com.br

${ }^{[b]}$ Doutor em Enfermagem em Saúde Pública pela Universidade de São Paulo (USP), câmpus Ribeirão Preto, Ribeirão Preto, SP - Brasil, e-mail: kebbe@fmrp.usp.br
}

Recebido: $18 / 11 / 2011$ Received: $11 / 18 / 2011$

Aprovado: $17 / 04 / 2012$ Approved: 04/17/2012

\begin{abstract}
Resumo
Este artigo objetiva apresentar a percepção de estudantes de diferentes cursos de graduação diante da atuação como estagiários no campo da saúde mental. Foi realizada uma revisão da literatura científica indexada, com a seleção de 11 artigos publicados em periódicos nacionais. Por meio de análise de conteúdo temática, houve a identificação de três categorias analíticas: 1. Sentimentos suscitados durante as práticas de estágio; 2. Preconceito para com o portador de transtorno mental; 3. Enfrentamento e superação das dificuldades advindas da prática. Os resultados encontrados apontaram as dificuldades dos estagiários, como sentimentos de medo e insegurança ante a perspectiva e durante a atuação obrigatória em saúde mental, sendo essas dificuldades decorrentes de uma construção histórica que envolve diferentes formas de se conceber e lidar com a "loucura". Os resultados sugerem que a inserção dos estagiários nas práticas de estágios os auxilia a desconstruir concepções equivocadas acerca da pessoa com transtorno mental, o que lhes favorece a aprendizagem.
\end{abstract}

Palavras-chave: Saúde mental. Estágio clínico. Percepção.

\begin{abstract}
This article aims to present the perceptions of students of different graduation courses in the health area about playacting, as trainees, in the field of Mental Health. It was performed a systematic review of the scientific literature indexed, having been selected 11 articles academics. Data were collected through the submission of articles to a previously elaborated protocol, including items of interest on the theme. By means of thematic content analysis, there was the identification of three analytical categories and thematic units: 1. Feelings raised during the practices of the probationary period; 2. Prejudice to the mental patient; 3. Face and overcome difficulties arising from the practice. Results confirmed the existence of difficulties, fears and uncertainties, on the part of students, in front of playacting compulsory perspective in Mental Health; those difficulties are fruit of a historical construction which involves different forms of conceiving and dealing with "madness". The results suggest that the insertion of the trainees at the practices of traineeships helps them to deconstruct equivocal concepts about the person with mental disorder, what they favor the learning.
\end{abstract}

Keywords: Mental health. Clinical clerkship. Perception.

Psicol. Argum. 2013 jul./set., 31 (74), 519-528 


\section{Introdução}

De acordo com a publicação da Secretaria de Saúde do Estado do Paraná (2009), a Organização Mundial de Saúde aponta para a inexistência de uma definição oficial de saúde mental. A mescla de diferenças culturais, julgamentos subjetivos e arcabouços teórico-metodológicos concorrentes afetam o modo como a saúde mental é concebida. Saúde mental pode aludir ao nível de qualidade de vida cognitiva ou emocional e considerar a capacidade de uma pessoa apreciar a vida. Sendo um conceito maior que ausência de transtornos mentais, a saúde mental também pode ser concebida como o bem-estar da pessoa consigo mesma e com seu entorno social, assim como sua flexibilidade para adaptar-se e responder às diferentes demandas do cotidiano.

Lancetti e Amarante (2006) assinalam a pluralidade de significados do termo "saúde mental" que, por ser um termo amplo, reporta-se a um campo profissional ou a uma área de atuação. Para esses autores, a atenção à saúde mental abrange conhecimentos e ações em que vários saberes se entrecruzam de forma interdisciplinar e intersetorial, como a psicologia, a psicanálise, a medicina, a história e a filosofia.

Para Oliveira e Dorneles (2005), a saúde mental não deve ser concebida como disciplina estanque, mas integradora de diferentes abordagens. Não deve, ainda, confundir-se com um conjunto de técnicas isoladas ou com tecnologias terapêuticas em um sentido estritamente médico.

Rabelo, Mattos, Coutinho e Pereira (2006) referem que os atuais cuidados em saúde mental devem transcender o uso de técnicas tradicionalmente reducionistas e incluir ações de ordem política que busquem a mudança de preconceitos e da cultura da população. Esses cuidados também devem forjar técnicas coerentes com as novas especificidades dos serviços de saúde mental, dispostos em uma rede no sistema de saúde.

Os autores citados sublinham a relação ética imprescindível para as ações de saúde mental, priorizando a inclusão social da pessoa com transtorno mental, objetivando a conquista de sua cidadania e da contratualidade social; essas questões são resultantes dos avanços da Reforma Psiquiátrica Brasileira.

O sofrimento psíquico e as ações de saúde mental vêm sendo estudados ao longo da história, a partir de diferentes perspectivas, e tal estudo tem passado por mudanças de acordo com o momento histórico, político, e cultural, também sendo influenciado pelos referenciais teórico-filosóficos existentes para pô-lo em prática. 0 próprio conceito de doença mental e de loucura tem sido revisado no decorrer do tempo, acompanhando as mudanças do mundo em relação aos valores, aos avanços científicos e aos novos entendimentos técnico-científicos da área da saúde.

Dutra (1999) refere que a associação entre loucura e periculosidade deu-se à época do Iluminismo, na chamada Idade da Razão na Europa, quando os alienados ("loucos") eram arbitrariamente excluídos do convívio social por serem considerados inaptos a participar produtivamente da sociedade (Lancetti \& Amarante, 2006). A pessoa considerada desprovida de razão, irracional, aproximava-se da ideia de animalidade e, consequentemente, de periculosidade; as manifestações dos loucos, em seus atos e expressões, eram julgadas moralmente pela sociedade e por serem interpretadas como sendo impulsivas e agressivas, o sujeito em desrazão era concebido como potencialmente perigoso e antissocial.

Ainda hoje, segundo Dutra (1999), pessoas diagnosticadas com transtornos mentais são, por vezes, representadas pelo imaginário popular como perigosas e ameaçantes à integridade social.

Para estudantes em formação nos cursos de graduação das diferentes áreas da saúde, a assimilação desses valores coletivos acerca do portador de transtorno mental e de suas singulares manifestações sintomáticas, mesmo que equivocados, comumente os faz crer que a pessoa com diagnóstico psiquiátrico grave e em episódio de crise, dadas as suas condições sintomáticas, seria descontrolada e perigosa.

Nesse sentido, Bandeira, Quaglia, Bachetti, Ferreira e Souza (2005) apontam que os estudantes tendem a vislumbrar a própria atuação nos estágios clínicos obrigatórios, junto a pacientes da área da saúde mental, mediante uma expectativa negativa, vivida com insegurança e ansiedade.

Espera-se que os cursos de graduação possibilitem aos acadêmicos o entendimento de que tais representações pejorativas, associadas à referida área e à sua população pertencente, resultam de complexos processos históricos, políticos, culturais e filosóficos de se conceber e tratar a denominada "loucura". Assim sendo, a representação da "loucura" associada à periculosidade é construída historicamente, gerando e reproduzindo preconceitos transmitidos entre gerações. Diante do desafio de vir a atuar na área de saúde mental, tais preconceitos e representações costumam ser 
recapitulados pelos estudantes, podendo se constituir em obstáculo para o aprendizado.

Por meio de uma revisão de artigos publicados em periódicos nacionais entre os anos 1996 e 2008, referentes à temática "estágio em saúde mental”, buscou-se acessar as experiências pelas quais passam os estudantes, de diferentes cursos de graduação, durante a realização de seus estágios curriculares obrigatórios em saúde mental. Com isso, objetivou-se um maior entendimento acerca da percepção dos estudantes a respeito de sua própria atuação enquanto estagiários e futuros profissionais na área da saúde mental, considerando-se as questões que essa prática costuma suscitar nos aprendizes.

\section{Desenvolvimento}

Realizou-se um estudo qualitativo descritivo com a seleção de 11 artigos indexados, provenientes das bases de dados: SciELO, PePSIC, BVS e Google Acadêmico. Para esse processo de seleção de artigos, adotaram-se os seguintes critérios: idioma em português; tipo de publicação (artigo); trabalhos publicados exclusivamente em uma das bases de dados mencionadas; título e resumo relacionados ao assunto-tema. Destaca-se, dentre as publicações selecionadas, a existência de relatos de pesquisa e também relatos de experiência em saúde mental. Oito trabalhos referiram-se a estágios realizados na área de enfermagem e três em psicologia. Os dados foram coletados dos artigos seguindo a questão norteadora: "Como os estagiários percebem e o que sentem durante sua atuação na área da saúde mental?”.

Esses dados, recortados e transcritos dos artigos, após leituras repetidas, foram submetidos à análise temática de conteúdo, conforme proposto por Minayo (1999). Três categorias analíticas emergiram dos procedimentos de análise: sentimentos suscitados durante as práticas de estágio; preconceito para com o portador de transtorno mental; enfrentamento e superação das dificuldades advindas da prática.

\section{Sentimentos suscitados durante as práticas de estágio}

A parte prática dos cursos de graduação na área da saúde faz que o estudante depare com uma realidade até então não contemplada por ele: a experiência de um estágio curricular, que traz ao aluno, pela primeira vez, na condição de aspirante a profissional, as demandas reais dos sujeitos em sofrimento psíquico decorrente de diferentes transtornos mentais. Isso gera uma gama de sentimentos ambivalentes e direcionados a diferentes objetos: ora para os pacientes, ora para os supervisores, e até mesmo para a teoria estudada.

Villa e Cadete (2000), docentes da área de Enfermagem, desenvolveram uma pesquisa qualitativa utilizando um questionário para alunos do 6o semestre do curso de Graduação em Enfermagem, com a pergunta: qual o sentido deste estágio para seu aprendizado de enfermeiro? Os alunos passavam pela disciplina de Enfermagem Psiquiátrica, com práticas de estágio realizadas em um Centro de Referência em Saúde Mental (CERSAM), nas quais realizavam atendimento a urgências psiquiátricas. A partir das respostas dos estudantes, submetidas a análise de conteúdo, ficaram evidentes sentimentos em relação à prática vivida: eles referiram tomar contato com suas próprias angústias ao serem expostos ao sofrimento dos pacientes.

No estudo de Paparelli e Nogueira-Martins (2007), realizado em um serviço de plantão psicológico de uma clínica-escola, estagiários atenderam pacientes que sofriam experiências traumáticas e que apresentavam necessidade de intervenção imediata. Nesse campo de estágio, estudantes do $9^{\circ}$ e do $10^{\circ}$ semestres de um curso de psicologia desenvolviam plantões de 12 horas, nos quais realizavam acolhimentos, entrevistas, intervenções imediatas com tempo limitado de 10 minutos, orientações e esclarecimentos, encaminhamentos e contato com familiares dos pacientes. Com o objetivo de analisar a forma como o aluno compreendia o atendimento psicológico à comunidade, foram realizados grupos focais com os estudantes, norteados por um roteiro de perguntas, e as respostas foram tratadas por meio de análise temática do conteúdo. Os resultados apontaram a referência dos alunos a sentimentos pessoais como ansiedade e insegurança. Segundo os acadêmicos, esses sentimentos emergiram da sua inserção em uma área desconhecida, e por terem de lidar com a primeira experiência prática em saúde mental. Esses estudantes também referiram angústia diante do sofrimento dos pacientes, e afirmaram que era difícil o manejo desse sentimento, o que lhes sugeria identificação com os sentimentos dos pacientes atendidos.

Bosquetti e Braga (2008) desenvolveram uma pesquisa com estudantes do $3^{\circ}$ e do $4^{\circ}$ ano de Graduação em Enfermagem, exercendo estágio curricular em

Psicol. Argum. 2013 jul./set., 31 (74), 519-528 
enfermarias de um hospital geral. 0 objetivo do estudo foi obter melhor entendimento sobre as emoções dos alunos, ao vivenciarem seu primeiro estágio curricular, fornecendo aos professores ferramentas para melhor trabalharem nessa etapa da formação acadêmica. Foram realizadas entrevistas com os estudantes, abordando-se o ambiente de trabalho e o relacionamento com as equipes, os pacientes e os docentes, sendo as respostas tratadas com análise de conteúdo. Nos resultados, os autores apontam aspectos positivos e negativos trazidos pelos estudantes sobre os temas constituintes da entrevista. Em relação aos sentimentos dos alunos, foram citadas ansiedade e insegurança, além de dificuldades de ordem pessoal, geradoras de angústia. Esses sentimentos eram despertados principalmente nos momentos em que esses estagiários necessitavam lidar com situações estressantes, tal como a morte dos pacientes internados no hospital onde atuavam. Ressalta-se que, embora o estudo não tenha sido realizado especificamente na área da saúde mental ou em serviço afim, as experiências de aprendizagem vividas cotidianamente pelos estagiários atentam à necessidade de acolhimento dos mesmos, para que reestruturem sua própria saúde mental. Assim, os supervisores de estágios devem considerar em seu trabalho de supervisão clínica, aspectos da vida emocional dos estudantes, acolhendo-os e encorajando-os em seu processo de formação profissional, valorizando igualmente o aprendizado teórico-técnico.

Scherer, Camargo e Villar (2001) descreveram sua experiência de estágio na área da enfermagem quando eram alunos do 6ํㅗㄹ semestre de graduação, objetivando provocar reflexões sobre o processo de ensino e de aprendizagem. Durante estágio curricular oferecido pela disciplina Enfermagem Psiquiátrica, os autores foram inseridos em um serviço de urgência psiquiátrica em uma unidade de emergência hospitalar. Nesse campo, se deu o atendimento a uma adolescente em sua primeira crise de doença mental; a menina estava internada em enfermaria psiquiátrica. Foram realizados diversos contatos com a paciente e com sua mãe, por meio das quais se desenvolveu o que foi chamado pelos estudantes de "relação de ajuda", caracterizada por interações em entrevistas periódicas para apoiar paciente e família até perceber-se a redução dos sintomas críticos. Sobre sua percepção quanto à prática, os estudantes constataram existência de sentimentos próprios como ansiedade e tensão diante dos questionamentos trazidos pela paciente sobre a sua melhora e a possibilidade de alta, além de referirem sentir angústia diante da percepção do sofrimento do outro.

Pessoa (1996) discorreu sobre aspectos que envolvem a prática em saúde mental, como as dificuldades encontradas no contato dos estudantes com pacientes sintomáticos e as especificidades do relacionamento terapêutico com a população acometida por transtornos psiquiátricos. Esses assuntos foram discutidos em um grupo de reflexão com estudantes do $7^{\circ}$ o semestre de graduação em enfermagem, que realizavam atividades práticas em um instituto de psiquiatria universitário, promovendo assistência de enfermagem a pessoas com dificuldade de integração social. A partir do grupo de reflexão, a autora descreve os sentimentos expressos pelos alunos como sendo ansiedade e insegurança para lidar com o desconhecido, e identificação com alguns conteúdos manifestados pelos pacientes.

Nesse sentido, os artigos desta categoria apontaram para referências semelhantes, elencadas pelos estudantes pesquisados; elas dizem respeito a sentimentos como angústia, insegurança e ansiedade, durante sua prática em saúde mental, além da ocorrência de um processo de identificação dos alunos com os pacientes por eles atendidos.

Segundo Bandeira et al. (2005), a ansiedade surge quando determinadas situações sociais são relacionadas a estímulos aversivos, talvez por conta de experiências anteriores, e surte efeito inibidor sobre o desempenho social e em particular sobre a capacidade de agir com assertividade - habilidade que envolve a afirmação dos próprios direitos e a expressão de pensamentos, sentimentos e crenças de forma direta, honesta e apropriada, sem violar os direitos de outras pessoas. A ansiedade é agravada pelo medo do conflito interpessoal e estudantes ansiosos podem apresentar dificuldades maiores em relação à comunicação verbal, ao controle pessoal, à autoestima e ao desempenho de papéis, culminando em menor assertividade e problemas no processo de ensino e aprendizagem.

Considerando os efeitos negativos provocados pela ansiedade, também ela própria geradora e agravadora da insegurança, torna-se evidente a situação de sofrimento e de impotência a que o estagiário pode experimentar, sentindo-se ameaçado por fatores externos e internos. Nessas condições, é natural que, conscientemente ou não, os estudantes comecem a defender-se ao perceberem-se identificados com o funcionamento psíquico dos pacientes e por eles mesmos viverem uma situação de 
sofrimento psíquico, considerando-se, naturalmente, as diferenças de intensidades desse sofrimento.

Ainda referindo-se aos sentimentos dos alunos despertados pelas práticas nos estágios, Paparelli e Nogueira-Martins (2007) indicam que os estudantes sentem medo de não saber o que fazer diante do paciente e de suas necessidades, medo de "se misturar" e de errar. Scherer et al. (2001) se aproximam dessa visão, ao compartilhar seus sentimentos decorrentes do contato com o paciente, descrevendo situações de ansiedade e de tensão em face de questionamentos do paciente sobre sua melhora e possibilidade de alta. Pessoa (1996) desenvolve reflexões semelhantes aos dos autores anteriores; em seu estudo, os estudantes referiram igualmente insegurança e ansiedade para agir ante as demandas dos pacientes e o desconhecido. Essa autora especifica os sentimentos gerados da relação estagiário-paciente, descrevendo também o medo por parte dos estudantes, por considerarem os pacientes potencialmente agressivos, e também a existência de dificuldades em falar sobre determinados assuntos com o paciente, como a sexualidade. Por fim, Bosquetti e Braga (2008) comentam que os alunos têm de não serem aceitos pelos pacientes, isso por causa da insegurança em realizar procedimentos pela primeira vez e demonstrar inabilidade.

No transcorrer de suas práticas enquanto estagiários, os estudantes experimentam diversas situações durante o treinamento profissional, a partir das quais afloram sentimentos multifacetados: o momento de ser colocado à prova, de aplicar seus conhecimentos, ser empático sem se identificar com o sofrimento alheio, mostrar-se assertivo nas intervenções, e tudo isso com a clareza de que há um sujeito envolvido, consciente, que o observa, interage e levará consigo opiniões e conceitos a seu respeito enquanto futuro profissional. Além disso, é a primeira vez no curso de graduação que o aluno se depara com a real responsabilidade que fundamenta sua profissão: é seu dever lidar com o paciente, e com a prática em geral, de uma forma consciente, reflexiva e honesta, e superar situações problemáticas envolvidas no cotidiano profissional.

Em dois dos artigos analisados, os autores aludiram ao temor dos estudantes, originado do contato com o supervisor e, nessa situação, apareceram principalmente inseguranças frente ao supervisor e à aplicação do conhecimento. Paparelli e Nogueira-Martins (2007) descreveram a referência dos estudantes ao medo de receberem críticas de seus supervisores durante sua prática, apesar de considerarem a supervisão um apoio positivo. Como mencionado, Bosquetti e Braga (2008) referiram a insegurança dos estudantes ao realizarem procedimentos antes vistos apenas em teoria, o medo de demonstrar inabilidade e, por isso, serem criticados. Nesse artigo, as autoras referiram, ainda, a visão dos estudantes sobre sua relação com os docentes responsáveis pela área prática: foi considerado um bom relacionamento aquele em que o docente era visto como prestativo, educado, paciente, capaz de esclarecer e amenizar inseguranças; em contrapartida, foi visto como um mau relacionamento aquele em que o docente foi considerado como preocupado excessivamente com a técnica e impaciente no momento de ensinar.

Evidencia-se uma relação ambivalente entre estudante e docente supervisor: em parte, o aluno considera o auxílio necessário e útil, e sente-se aliviado ao recebê-lo; por outro lado, os sentimentos identificados anteriormente (ansiedade, insegurança) podem exercer um efeito negativo e gerar certa resistência à escuta. Nesse caso, orientações e tentativas de ensino pelo supervisor podem ser vistas como críticas destrutivas e perseguições, o que afasta o estagiário de quem poderia ser uma fonte de segurança em um momento de descobertas.

Reitera-se a importância de o supervisor desenvolver "escuta" junto ao seu estagiário, acolhendo-o nos momentos ansiogênicos, buscando amenizar seu sofrimento para melhor nortear sua aprendizagem.

Nesse sentido, de acordo com Anastasiou (2003), concebe-se que ensinar não é apenas transmitir conhecimentos, assim como aprender não é apenas registrar conteúdos técnicos sem compreendê-los, sendo imprescindíveis o respeito pela autonomia do acadêmico e por sua identidade cultural e a valorização de seus saberes prévios. Assim sendo, a capacidade para a escuta e a disponibilidade para o diálogo constituem ferramentas importantes para a tarefa de ensinar, favorecendo a construção conjunta do conhecimento, em uma parceria estabelecida entre professores e estudantes.

\section{Preconceito para com o portador de transtorno mental}

Além dos conflitos pelos quais passaram os alunos, parte dos artigos estudados mencionaram também questões acerca da expectativa dos estudantes sobre o que esperavam encontrar nos pacientes

Psicol. Argum. 2013 jul./set., 31 (74), 519-528 
com transtornos mentais, em termos de sua aparência e de seus comportamentos.

A partir dos contatos com os pacientes, os alunos puderam confrontar suas próprias crenças pré-concebidas acerca da "loucura perigosa" ao se depararem com pessoas que aprentemente não se diferenciavam deles mesmos. A diferença estava na forma intensa pela qual os pacientes expressavam seu sofrimento psíquico. Nesse sentido, alguns artigos abordaram a questão do preconceito em relação ao sujeito acometido por transtornos mentais, recapitulando o que foi exposto neste artigo sobre a imagem e os comportamentos de periculosidade culturalmente sancionados, atribuídos e esperados dos portadores de enfermidades mentais.

Souza e Campos (1999) relataram sua experiência prática na área de psicologia em um estágio supervisionado realizado em consultório, uma mulher com esquizofrenia recebeu atendimento, englobando desde a avaliação diagnóstica até o tratamento global com psicoterapia de apoio. Posteriormente, realizou-se visita domiciliar para verificar de que forma ocorreria a inserção da paciente na dinâmica familiar. Nesse relato de caso, os autores expuseram seus sentimentos, prévios ao contato com a paciente em questão, tais como o medo e a angústia que sentiram diante da tarefa de atender uma pessoa portadora de esquizofrenia. Esses sentimentos foram suscitados pelo significado "assustador" subjacente ao referido diagnóstico, segundo os autores.

Villa e Cadete (2000) também reportaram que estudantes sentem medo em relação à expectativa do contato com pessoas que apresentavam sintomas psiquiátricos. 0 medo, conforme referido no estudo de Pessoa (1996), sugeriu que os estudantes consideravam os pacientes psiquiátricos como potencialmente agressivos, antes mesmo de conhecê-los. Scherer et al. (2001), por sua vez, descreveram sensação de estranhamento ao encontrarem uma paciente na faixa etária da adolescência, e com a aparência de uma pessoa sem qualquer tipo de transtorno psiquiátrico.

Os sentimentos originados da lida (ou antes mesmo do encontro) com a população atendida pelos estagiários e as percepções por eles expressas sugerem quão arraigados podem estar os preconceitos, e também quão infundados podem ser quando se parte do princípio de que a manifestação sintomática do transtorno psíquico teria, necessariamente, características ameaçadoras, destrutivas e agressivas. Nessa perspectiva, cabe reiterar a importância do trabalho conjunto com os supervisores clínicos e os docentes das diferentes áreas, pois estes devem auxiliar os estudantes a desconstruírem a imagem estigmatizada do paciente psiquiátrico, buscando facilitar a relação terapêutica e o processo de ensino e de aprendizagem.

\section{Enfrentamento e superação das dificuldades advindas da prática}

Nos artigos analisados observou-se que, a partir das diferentes experiências vividas nos estágios e com a ajuda constante e adequada dos supervisores, também do estudo teórico, o estudante passou a lidar melhor com o próprio sofrimento e, especialmente, com o sofrimento dos pacientes atendidos. Além disso, a imagem do paciente como sendo potencialmente ameaçador pôde ser desconstruída, dando lugar a uma percepção mais positiva da pessoa atendida, como alguém que carece de atenção especializada e afetiva. Isso contribuiu para um maior envolvimento do estudante em suas atividades teórico-práticas. 0 acadêmico passou a almejar uma melhor oferta de cuidados para com as pessoas sob sua responsabilidade, ao longo dos estágios.

Camillo, Silva e Nascimento (2007) estudaram a experiência de alunos que cursavam enfermagem, durante um estágio realizado na área de saúde mental. Buscaram, em seu estudo, investigar se os estudantes valorizariam os aspectos emocionais dos sujeitos atendidos, se reconheceriam as contribuições do estágio realizado à sua vida profissional e também à pessoal. Realizaram-se entrevistas semiestruturadas com os alunos que já haviam encerrado o $5^{0}$ semestre do curso de graduação, momento em que ocorriam as práticas de estágio, e submeteram-se as respostas à análise de conteúdo. Os alunos mencionaram que a visão estigmatizada da loucura e as dificuldades encontradas na prática foram sendo superadas à medida que eles conseguiram ampliar sua visão sobre o ser humano, considerando assim sua dimensão psicológica e a importância das relações interpessoais. Com tal mudança, os estudantes referiram satisfação no aprendizado adquirido e sentiram-se mais estimulados e interessados pela área da saúde mental.

Campoy, Merigui e Stefanelli (2003) analisaram o processo de ensino e de aprendizagem desenvolvido a partir de uma disciplina denominada Enfermagem e Saúde Mental, na ótica dos docentes e dos alunos 
que dela participaram. No que concerne aos estudantes, estes foram entrevistados após terem concluído a disciplina, e suas respostas trouxeram notável reconhecimento sobre a superação das dificuldades iniciais e de sua transformação de conduta. Esses acadêmicos reportaram perceber a importância da comunicação interpessoal e das relações interpessoais: aprender a ver o outro como pessoa; reconhecer o significado do autoconhecimento; sentir-se motivado a mudar de atitude; superar preconceitos; e desenvolver maior interesse pela futura atuação profissional na área de saúde mental.

Villa e Cadete (2000) observaram que, ao longo do estágio, o medo dos pacientes cedeu lugar à necessidade de auxiliá-los, o que trouxe aos estudantes sentimentos de liberdade e de utilidade. Ao fim da prática, o estágio foi considerado pelos alunos entrevistados como uma experiência importante, por mudar mitos e preconceitos. Souza e Campos (1999), assim como Pessoa (1996), encontraram nas percepções dos alunos resultados também positivos ao término das experiências de estágio. Nos artigos desses autores, os estudantes apontaram que, após seu período de prática e de enfrentamento de seus medos, identificaram sentimentos positivos em relação à ajuda proporcionada aos pacientes, além de maior compreensão sobre esses sujeitos, desmistificação de preconceitos e gratificação com o trabalho desenvolvido.

Além das supervisões contínuas, o encerramento e a avaliação crítico-reflexiva das atividades de estágio, realizadas pelos estudantes junto de seus supervisores e docentes, podem constituir um momento ímpar para o processo de aprendizagem, possibilitando que o estudante analise com mais clareza as diversas dificuldades por que passou, observando e ressignificando o próprio percurso. 0 estagiário pode reconhecer, por exemplo, que a visão estereotipada sobre o paciente psiquiátrico interfere no aprendizado e na qualidade das práticas realizadas e pode, também, observar que, paulatinamente, consegue desconstruir esse olhar à medida que supera sentimentos negativos, integra-se ao local de trabalho e à equipe (na qual incluem-se os supervisores) e desenvolve empatia para com o paciente.

A compreensão do papel profissional pelos estudantes surge como uma das aquisições do processo de enfrentamento e superação das dificuldades encontradas no estágio.

Após toda a trajetória percorrida pelos acadêmicos, sujeitos de estudo dos artigos analisados, desde os sentimentos iniciais conflitantes, a incompreensão e a inaceitação da "loucura", até o enfrentamento de medos e de preconceitos, nota-se que a maioria dos alunos apontou que a experiência de estágio foi válida porque propocionar aprendizado e uma compreensão autêntica de seu papel profissional. Nos artigos estudados, os acadêmicos referiram sua experiência de estágio como rica e repleta de aprendizado, ao possibilitar o trabalho em equipe, estabelecer contato com diferentes profissões em diferentes contextos de atuação, compreender a dimensão de sua prática e dominar aspectos técnicos, e apropriar-se de sua profissão.

Paparelli e Nogueira-Martins (2007) constataram que, após a experiência em plantão psicológico, os alunos compreenderam este campo de prática não como resolução imediata para todos os problemas dos usuários, mas como uma alternativa na busca pela transposição de alguns obstáculos vividos pelos pacientes.

Vaie e Barros (2001) descreveram sua atuação enquanto estagiárias em um Centro de Atenção Psicossocial (CAPS), durante a disciplina Enfermagem Materno-Infantil e Psiquiátrica, do 8o período de graduação. As autoras utilizaram como objeto de análise a equipe coordenadora de um grupo terapêutico do CAPS, composta por um psicólogo, um terapeuta ocupacional e um psiquiatra, que responderam a uma entrevista sobre o modelo assistencial desenvolvido no CAPS e a inserção do enfermeiro nesse serviço. Ao final, as autoras relataram que a atuação nesse estágio foi uma experiência valiosa, em que foi possível vivenciar o funcionamento em equipe de uma forma produtiva, com trocas de experiências e saberes; compreenderam também que o papel do enfermeiro pode ir além dos limites impostos pelos hospitais, e que é importante manter um contato direto com o paciente e uma relação adequada com a equipe.

Bosquetti e Braga (2008) discorreram, também, sobre os aspectos relacionais em equipe multidisciplinar, dessa vez a partir de diferentes pontos de vista: alguns estudantes referiram ter desenvolvido relacionamentos de cooperação em equipe; outros, porém, referiram relações distantes e de simples transmissão de informações, o que prejudicava o trabalho da equipe como um todo e, consequentemente, a assistência aos pacientes.

Moreira (2003) apresentou uma análise das supervisões realizadas pelos docentes de psicologia com alunos do mesmo curso durante seu estágio curricular obrigatório em clínica-escola. Nesse estágio, os

Psicol. Argum. 2013 jul./set., 31 (74), 519-528 
estudantes realizavam atendimentos com pessoas da comunidade, orientações às famílias, triagens e encaminhamento para serviços disponíveis na mesma instituição ou em outra. 0 ponto principal do estágio, no entanto, era a realização de entrevistas para investigação da demanda que motivou a procura pelo serviço. A autora discutiu, a partir de sua ótica, a experiência dos estudantes, referindo perceber neles desenvolvimento de confiança e maturidade na exposição de casos à equipe, durante supervisões; desenvolvimento de postura atenta de acolhimento e escuta ao paciente e surgimento de propostas de intervenção em diferentes contextos, mostrando interesse, iniciativa e apropriação da abrangência de sua profissão.

Bousso, Merighi, Rolim, Riesco e Angelo (2000) descreveram a inserção de uma disciplina de estágio em um curso de enfermagem, nas áreas de Saúde da mulher, Infância e adolescência e Psiquiatria, com o objetivo de analisar o processo de ensino e de aprendizagem e a organização do estágio na visão dos docentes. As atividades práticas referentes ao estágio foram desenvolvidas em instituições hospitalares e extra-hospitalares, orientadas por três áreas específicas: "a criança hospitalizada e sua família", "o processo de cuidar do binômio mãe e filho na fase perinatal" e o "processo de cuidar em saúde mental com ênfase na reabilitação psicossocial”. Na saúde mental, especificamente, os alunos passaram por: Centro de Atenção Psicossocial, Centro de Reabilitação e Hospital Dia. Analisando tal disciplina, os autores relataram ter recebido de seus alunos devolutivas positivas sobre o estágio, considerado importante uma vez que lhes proporcionou segurança emocional e profissional, autonomia na atuação e busca de conhecimento científico que embasasse a prática. Esse processo culminou, inclusive, na contratação de alguns alunos nas mesmas instituições onde realizaram estágio.

A apropriação da profissão escolhida é uma aquisição de extrema importância para quem percorreu um longo processo na graduação e se vê próximo a alcançar a vida profissional, especialmente a partir da consecução dos estágios. Nota-se que o estágio propicia experiências que ampliam a visão dos estudantes quanto às possibilidades de intervenção em sua área e na saúde em geral. Nos artigos estudados, por exemplo, há referências dos estudantes à abordagem interdisciplinar em saúde mental, retratada pelas vivências em equipes em diversos contextos de atuação. Isso permite que ocorra a formação de profissionais mais conscientes e atuantes no sentido de compreender e empreender uma prática ampliada e colaborativa, que possa olhar para o sujeito atendido em todos os seus aspectos constituintes: biológicos, psicológicos, sociais, culturais e políticos.

\section{Considerações finais}

Embora retratem experiências vividas prioritariamente por estagiários das áreas da psicologia e da enfermagem, os resultados desta revisão de literatura apontaram para questões aqui consideradas como sendo universais. Sentimentos como medo, ansiedade e angústia, e também a existência de preconceitos, por parte dos acadêmicos em fase de treinamento profissional podem perpassar e obstruir a aprendizagem e as práticas em saúde mental, nas diversas áreas e contextos da saúde. 0 aprendizado pleno e a apropriação profissional tendem a ser adquiridos quando os estudantes conseguem refletir criticamente sobre suas vivências e superar seus conflitos.

Os estágios em saúde mental, por vezes constando como obrigatórios nos currículos universitários, geram nos alunos uma diversidade de crenças, passíveis de atuarem como elementos prejudiciais no processo de ensino e de aprendizagem. A forma como o imaginário coletivo tem representado as manifestações sintomáticas de portadores de transtornos mentais, vulgarmente conhecidas como "loucura", atemoriza os alunos. Estes, ao reproduzirem essa representação, podem inicialmente tornar-se inábeis para enxergar as pessoas em sofrimento psíquico, especialmente quando valorizam seus sentimentos particulares, tais como o medo de ser agredido, suas próprias angústias e a identificação com os pacientes. Acresce-se a isso a proximidade do início da vida profissional e a responsabilidade de realizar, com êxito, o primeiro estágio. Esses fatores podem gerar ou elevar a angústia dos alunos. Conforme apontado nos artigos analisados, os acadêmicos podem se sentir na obrigação de agir como se estivessem totalmente preparados para a atuação profissional, com considerável bagagem de experiência. Eles se sentem frustrados ao receber orientações e correções de seus supervisores, que buscam ajudá-los a desenvolver habilidades profissionais para que possam realizar, satisfatoriamente, suas práticas de estágio e também no futuro, na condição de profissionais.

Observou-se que, a partir do contato com o paciente, o estudante tende a desenvolver uma visão 
diferenciada e menos preconceituosa a respeito da pessoa com transtorno mental. Por essa razão, é imprescindível ao acadêmico desenvolver experiência de lida com o paciente para que então comece a desconstruir, em alguma medida, concepções pejorativas sobre a população atendida.

Essa mudança de perspectiva pode ser facilitada com a realização de estudos teóricos supervisionados, o que permite que os alunos compreendam o funcionamento psíquico dos sujeitos que encontram. Entender a situação emocional dos pacientes, o seu sofrimento, e desenvolver um senso de empatia são tarefas essenciais para o estudante e, para tanto, o auxílio contínuo, competente e afetivo dos docentes e dos supervisores é altamente relevante.

Conforme mostraram os artigos estudados, envolver-se com a prática, com os pacientes e consigo mesmo pode ser uma experiência extremamente gratificante para o estudante. Existe algo imensurável no momento em que se consegue olhar, sem preconceitos, para uma pessoa em sofrimento mental e sentir necessidade de lhe oferecer ajuda. Os estudantes sentem-se úteis e satisfeitos ao compreenderem seu papel profissional e apreenderem as ferramentas de que dispõem para trabalhar em saúde mental, a fim de de amenizar o sofrimento alheio, possibilitando, sempre que possível, uma vida mais saudável à pessoa com transtorno mental.

As questões levantadas neste artigo contribuem para o meio acadêmico fornecendo um panorama geral sobre os aspectos que envolvem o processo de ensino e de aprendizagem na área da saúde mental. Buscou-se, aqui, despertar reflexões e sensibilizar estudantes, docentes e profissionais supervisores da área de saúde mental para que reflitam sobre a importância de construir caminhos que facilitem a aquisição de habilidades e de conhecimentos para a atuação na referida área, minimizando o impacto inicial que as práticas realizadas junto a pacientes com transtornos mentais costumam causar.

\section{Referências}

Anastasiou, L. G. C. (2003). Ensinar, aprender, apreender e processo de ensinagem. In L. G. C. Anastasiou \& L. P. Alves (Org.). Processos de ensinagem na universidade: Pressupostos para estratégias de trabalho em aula (pp. 12-35). Joinville: Univille.
Bandeira, M., Quaglia, M. A. C., Bachetti, L. S., Ferreira, T. L., \& Souza, G. G. (2005). Comportamento assertivo e sua relação com ansiedade, lócus de controle e auto-estima em estudantes universitários. Estudos de Psicologia, 22(2), 111-121.

Bosquetti, L. S., \& Braga, E. M. (2008). Reações comunicativas dos alunos de enfermagem frente ao primeiro estágio curricular. Revista da Escola de Enfermagem da USP, 42(4), 690-696.

Bousso, R. S., Merighi, M. A. B., Rolim, M. A., Riesco, M. L. G., \& Angelo, M. (2000). Estágio curricular em enfermagem: Transição de identidades. Revista da Escola de Enfermagem da USP, 34(2), 218-225.

Camillo, S. O., Silva, A. L., \& Nascimento, A. J. (2007). Perceptions of nursing undergraduate students concerning the human dimension in the learning process. Revista Latino-Americana de Enfermagem, 15(2), 207-213.

Campoy, M. A., Merighi, M. A. B., \& Stefanelli, M. C. (2003). $\mathrm{O}$ ensino de enfermagem em saúde mental e psiquiátrica: Visão do professor e do aluno na perspectiva da fenomenologia social. Revista Latinoamericana de Enfermagem, 13(2), 165-172.

Dutra, M. C. B. (1999). As relações entre psicose e periculosidade: Contribuições clínicas da percepção psicanalítica da passagem ao ato. Dissertação de Mestrado em Psicologia, Universidade Federal de Minas Gerais, Belo Horizonte.

Lancetti, A., \& Amarante, P. (2006). Saúde mental e saúde coletiva. In G. W. S. Campos, M. C. S. Minayo, M. Akerman, M. Drumond Júnior \& Y. M. Carvalho (Org.). Tratado de saúde coletiva (pp. 615-634). São Paulo: Hucitec; Rio de Janeiro: Fiocruz.

Minayo, M. C. S. (1999). O desafio do conhecimento: Pesquisa qualitativa em saúde. São Paulo: Hucitec; Rio de Janeiro: Abrasco.

Moreira, M. I. B. (2003). 0 estágio de psicologia e a preparação para o cotidiano profissional. Cadernos de Psicologia, 13, 99-112.

Oliveira, W. F., \& Dorneles, P. (2005). Patrimônio e ambiente da loucura: A formação do profissional de saúde mental e o diálogo com a vida da cidade. In P. Amarante (Org.). Archivos de saúde mental e atenção psicossocial. (Vol. 2, pp. 13-43). Rio de Janeiro: Nau.

Psicol. Argum. 2013 jul./set., 31 (74), 519-528 
Paparelli, R. B., \& Nogueira-Martins, M. C. F. (2007). Psicólogos em formação: Vivências e demandas em plantão psicológico. Psicologia: Ciência e. Profissão, 27(1), 64-79.

Pessoa, C. K. L. (1996). Revelando a diferença. Revista Enfermagem UERJ, 4(n. esp.), 60-70.

Rabelo, A. R., Mattos, A. A. Q., Coutinho, D. M., \& Pereira, N. N. (2006). Um manual para o CAPS: Centro de atenção psicossocial. (2.ed. rev. e ampl.) Salvador: Edufba.

Scherer, Z. A. P., Camargo, J. S., \& Villar, L. M. A. (2001). Experiência de acompanhamento em estágio supervisionado de enfermagem psiquiátrica: Estudo de caso. Cogitare Enfermagem, 6(1), 7-3.

Secretaria de Saúde do Estado do Paraná (2009). Definição de Saúde Mental. Recuperado em 18 set. 2013, de http://www.sesa.pr.gov.br/modules/conteudo/conteudo.php?conteudo=2862
Souza, J. C. R. P., \& Campos, G. (1999). Esquizofrenia: Uma experiência acadêmica. Informação psiquiátrica, 18(3), 96-98.

Vaie, S., Barros, S. (2001). A vivência de um estudante de enfermagem em uma equipe interdisciplinar: Fábrica de idéias. Revista da Escola de Enfermagem da USP, 35(2), 100-107.

Villa, E. A., Cadete, M. M. M. (2000). Portas abertas: Novas possibilidades no ensino da enfermagem psiquiátrica. Revista Latino-Americana de Enfermagem, 8(6), 13-19. 